\title{
Effect of iontophoresis on fluoride uptake in enamel with artificial caries lesion
}

\author{
Maria Cibelle PAULI (a) iD \\ Cínthia Pereira Machado \\ TABCHOURY(b) \\ Silas Arandas Monteiro e SILVA(a) \\ Gláucia Maria Bovi AMBROSANO(b) \\ Renata Fonseca Vianna LOPEZ(c) \\ Gislaine Ricci LEONARDI(d) iD \\ (a) Universidade Federal de São Paulo - \\ Unifesp, Medicine Department, São Paulo, \\ SP, Brazil. \\ (b) Universidade de Campinas - Unicamp, \\ Piracicaba Dental School, Piracicaba, \\ SP, Brazil. \\ (c) Universidade de São Paulo - USP, School \\ of Pharmaceutical Sciences, Ribeirão Preto, \\ SP, Brazil. \\ (d) Unversidade Estadual de Campinas - \\ Unicamp, Faculty of Pharmaceutical \\ Sciences, Campinas, SP, Brazil.
}

Declaration of Interests: The authors certify that they have no commercial or associative interest that represents a conflict of interest in connection with the manuscript.

Corresponding Author:

Gislaine Ricci Leonardi

E-mail: gislaine.leonardi@fcf.unicamp.br

htps://doi.org/10.1590/1807-3107bor-2019.vol33.0037

Submitted: August 15, 2017

Accepted for publication: February 26, 2019

Last revision: March 29, 2019
Abstract: Iontophoresis is a noninvasive technique, based on the application of a constant low-intensity electric current to facilitate the release of a variety of drugs, whether ionized or not, through biological membranes. The objective of this research was to evaluate the effect of iontophoresis using different electric current intensities on the uptake of fluoride in dental enamel with artificial caries lesions. In this in vitro operator-blind experiment, bovine enamel blocks ( $n=10$ /group) with caries-like lesions and predetermined surface hardness were randomized into 6 groups: placebo gel without fluoride applied with a current of 0.8 $\mathrm{mA}$ (negative control), $2 \% \mathrm{NaF}$ gel without application of any current, and $2 \% \mathrm{NaF}$ gel applied with currents of $0.1,0.2,0.4$ and $0.8 \mathrm{~mA}$. Cathodic iontophoresis was applied for $4 \mathrm{~min}$. The concentration of loosely bound fluoride (calcium fluoride) and firmly bound fluoride (fluorapatite) was determined. The results were analyzed by the nonparametric KruskalWallis and Dunn tests. Iontophoresis at $0.8 \mathrm{~mA}$, combined with the application of fluoridated gel $(2 \% \mathrm{NaF})$, increased fluoride uptake in enamel with caries-like lesions, as either calcium fluoride or fluorapatite.

Keywords: Iontophoresis; Dental Caries; Dental Enamel; Calcium Fluoride.

\section{Introduction}

Iontophoresis is a noninvasive technique, based on the application of a constant low-intensity electric current to facilitate the release of a variety of drugs, whether ionized or not, through biological membranes. ${ }^{1}$ The electrical current is supplied by a battery or power source, and is distributed via positive (anode) and negative (cathode) electrodes through an electrolytic solution. When the current is applied, the cations that are in contact with the anode move in the direction of the cathode, whereas the anions at the cathode move in the opposite direction., ${ }^{1,2}$ Several studies evaluated the influence of iontophoresis on enhancing the skin penetration of drugs, and assessed its applicability as a tool in treating skin and eye diseases. ${ }^{3,4,5}$

One of the advantages of using iontophoresis in dentistry is that it is a non-invasive method, whereby the drugs are administered directly at the treatment site with minimized adverse effects. ${ }^{6,7}$ Data on the use of iontophoresis with dental substances or compounds is still sparse in the 
scientific literature. However, there are some reports that highlight the positive results of using fluoride by iontophoresis among the various treatments offered for desensitization of hypersensitive dentin, by enabling the transfer of this ion to the dentinal tubules. ${ }^{8}$

Dental caries is a biofilm-sugar induced disease that is triggered by biofilm accumulation on the tooth surface and regular exposure to dietary carbohydrates. ${ }^{9}$ Fluoride has a relevant effect on the caries development process due to its physicochemical action of decreasing demineralization and improving remineralization, when the biofilm $\mathrm{pH}$ drops after sugar exposure and then rises again. ${ }^{10}$ Fluoride has been added to several commercial products for individual and professional use. ${ }^{9}$ Moreover, it is well known that fluoride applied to tooth surfaces reacts with enamel to form two products: loosely bound fluoride (calcium fluoride-like material, $\mathrm{CaF}_{2}$ ) and firmly bound fluoride (fluorapatite, FA). Since $\mathrm{CaF}_{2}$ has been reported to be responsible for the effect of fluoride on caries control, ${ }_{11}^{11}$ it is important to evaluate how fluoride formulations are able to form this type of compound. Nevertheless, dental caries is still considered one of the most prevalent chronic diseases ${ }^{12}$ and the development of new therapeutic strategies to improve fluoride uptake by the dental substrate is expedient. Thus, the objective of this research was to evaluate the effect of iontophoresis with different electric current intensities on fluoride uptake in dental enamel with artificial caries lesion.

\section{Methodology}

This study was approved by the Research Ethics Committee of the Federal University of São Paulo (UNIFESP), under protocol number 9249041114.

\section{Experimental design}

In this in vitro operator-blind experiment, bovine enamel blocks ( $n=10 /$ group) with caries-like lesions and predetermined surface hardness values, were randomized into 6 groups: placebo gel without fluoride applied with a current of $0.8 \mathrm{~mA}$ (negative control), $2 \% \mathrm{NaF}$ gel without application of any current, and $2 \% \mathrm{NaF}$ gel applied with currents of 0.1, 0.2, 0.4 and $0.8 \mathrm{~mA}$. The enamel blocks with caries lesions were randomized into the experimental groups so that the mean value of surface hardness loss percentage (\%SHL) of each group did not statistically differ from the other groups. The dental blocks with caries lesions were treated with the gels for $4 \mathrm{~min}$ at room temperature. The fluoride formulation contained sodium fluoride $(\mathrm{NaF})$ in a $2 \%$ concentration, embedded in a gel composed of carboxymethyl cellulose and propylene glycol. All the formulations had a final $\mathrm{pH}$ of 6.0. The enamel surface hardness was determined a second time right after the treatments, and the percentage of surface hardness recovery was calculated. Then, loosely bound fluoride (calcium fluoride-like material; $\mathrm{CaF}_{2}$ ) was extracted with $\mathrm{KOH}$ and analyzed by an F-specific ion electrode. Next, two consecutive layers of enamel were removed from the dental blocks after acid etching, and firmly bound fluoride (fluorapatite; FA) was determined by an F-specific ion electrode.

\section{Preparation and initial selection of enamel blocks}

Healthy bovine incisors were stored in a $2 \%$ formaldehyde $\mathrm{pH} 7.0$ solution for a period of at least 30 days for disinfection before conducting any experimental procedure. ${ }^{13}$ Enamel blocks $(4 \times 4 \times 2 \mathrm{~mm})$ were obtained and the dentine was flattened. Afterwards, the enamel surface was flattened and polished. The dental blocks were selected by measuring the surface hardness at the central region of each block from three indentations, at a distance of $100 \mu \mathrm{m}$ between each other, using a Future Tech microhardness tester (Future-Tech FM Corp., Tokyo, Japan), FM-7 model, coupled to FM-ARS software and a Knoop penetrator, with a $50 \mathrm{~g}$ load for $5 \mathrm{~s} .^{14}$ The selection criteria was based on the mean and standard deviation of the surface hardness values of each dental block. Dental blocks with standard deviation greater than $10 \%$ were excluded from the experiment. The dental blocks were also visually analyzed for cracks or stains, in which case they were excluded.

\section{Induction of artificial carious lesion in enamel}

According to the Queiroz et al. ${ }^{15}$ protocol, 132 enamel blocks, initially selected by surface hardness, were immersed in $0.05 \mathrm{M}$ acetate buffer 
pH 5.0, containing $1.28 \mathrm{mmol} / \mathrm{L} \mathrm{Ca}, 0.74 \mathrm{mmol} / \mathrm{L} \mathrm{Pi}$ (inorganic phosphorus) and $0.03 \mu \mathrm{g} / \mathrm{mL}$ for $16 \mathrm{~h}$, at $37^{\circ} \mathrm{C}$, without shaking. This demineralizing solution is $50 \%$ saturated in respect to dental enamel, and induces a typical subsurface demineralization with no characteristics of erosion. ${ }^{16}$ Surface hardness analysis of the carious enamel blocks was performed a second time under the same conditions as those described above, and the percentage of surface hardness loss ([\%SHL $=100$ (SH after caries induction - baseline $\mathrm{SH}$ )/ baseline $\mathrm{SH}]$ ) was calculated.

\section{Reaction of fluoride gel with dental blocks associated with or without iontophoresis application}

A device to place the enamel block in contact with the formulations was developed to trigger the reaction of the gels with the dental blocks (Figure 1). The enamel area exposed to the formulation was $16 \mathrm{~mm}^{2}$. Two grams of each formulation was used in the donor compartment (Figure 2). A chloride silver electrode (cathode) was inserted in the donor compartment, and a silver electrode (anode) was placed on the side of the cell, against the dental block, thus closing the electrical circuit for the passage of electric current (Figure 3). Different intensities of constant electric current were applied with an electric

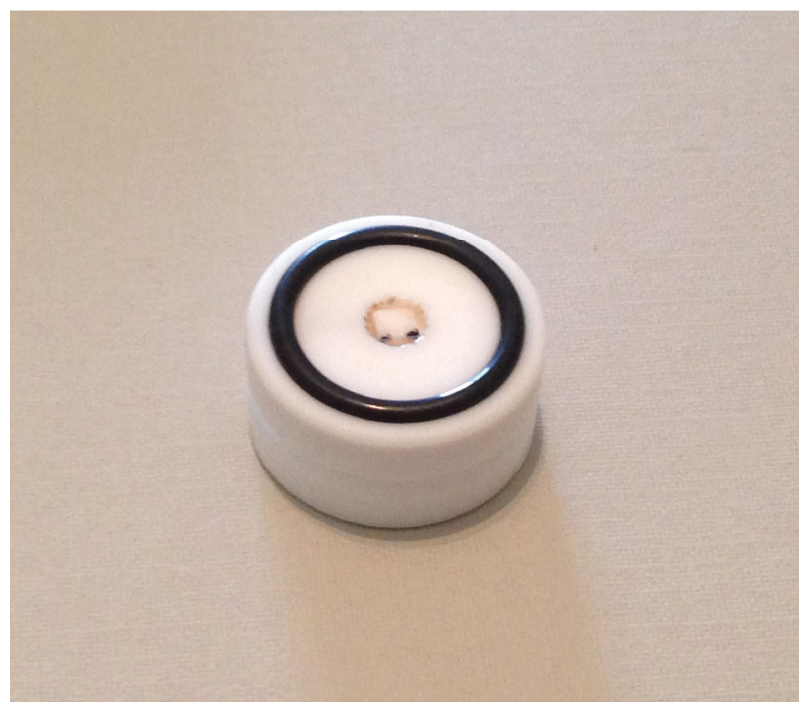

Figure 1. Acrylic apparatus where the dental enamel block was placed at the center. source (FUTRON) for $4 \mathrm{~min}$ at room temperature. After this time, the dental blocks were removed from the device and evaluated for surface hardness and concentration of loosely and firmly bound fluoride.

\section{Preparation of electrodes}

Silver $(\mathrm{Ag})$ and silver chloride $(\mathrm{AgCl})$ electrodes were prepared, ${ }^{17}$ using a silver wire dipped in molten

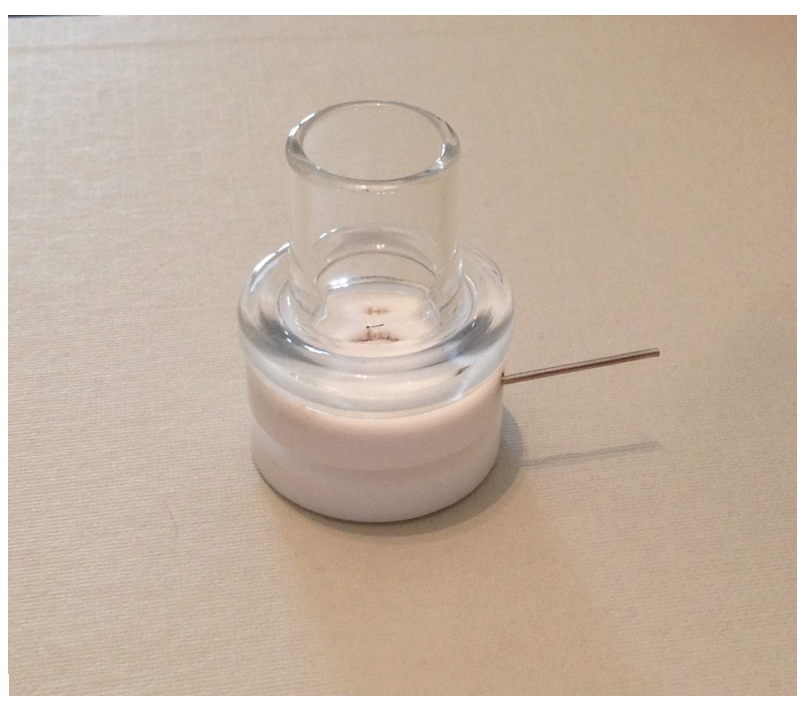

Figure 2. Glass apparatus placed over the acrylic apparatus, where $2 \mathrm{~g}$ of the formulation was added. At the side of the acrilic apparatus, there was an orifice, where the silver wire was placed, getting into contact with the side of the dental block.

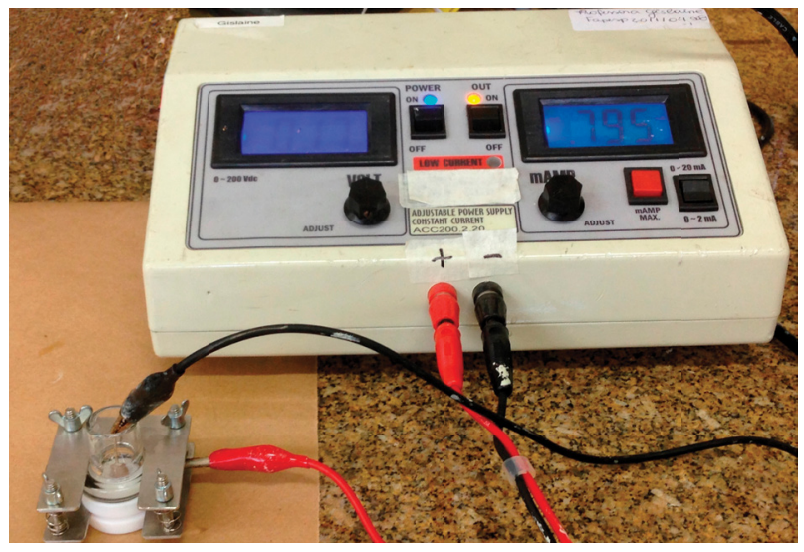

Figure 3. Iontophoresis equipment, showing a connected chloride silver electrode (cathode) inserted in the donor compartment and a silver electrode (anode) placed on the side of the cell, against the dental block, thus closing the electrical circuit for the passage of electric current. 
silver chloride in a porcelain crucible, and bent at one end. The negatively charged electrode (cathode) was obtained with solidification of the silver chloride at the end of the silver wire.

\section{Surface hardness evaluation after the treatments}

After receiving the treatments, each block was washed with purified water and again submitted to surface hardness analysis, with the same specifications already described. The percentage of surface hardness recovery $([\% \mathrm{SHR}=100(\mathrm{SH}$ after treatment $-\mathrm{SH}$ after caries induction)/(baseline $\mathrm{SH}$ - $\mathrm{SH}$ after caries induction])) was calculated.

\section{Determination of fluoride uptake in enamel}

The loosely bound fluoride was extracted by immersing the blocks individually in $0.5 \mathrm{~mL}$ of $1.0 \mathrm{M}$ $\mathrm{KOH}$ solution at room temperature and agitating gently for $24 \mathrm{~h} .{ }^{18}$ The extract was then neutralized with $0.5 \mathrm{~mL}$ of TISAB II containing $1.0 \mathrm{M} \mathrm{HCl}$ and analyzed with a fluoride-specific electrode coupled to a previously calibrated ion analyzer. The loosely bound fluoride formed on the enamel blocks was expressed as $\mu \mathrm{g} \mathrm{F} / \mathrm{cm}^{2}$. The firmly bound fluoride was extracted by removing two consecutive layers of enamel from the blocks after immersing them first in $0.25 \mathrm{~mL}$ of $0.5 \mathrm{M} \mathrm{HCl}$ for $15 \mathrm{~s}$ and then in fresh acid for another $15 \mathrm{~s}$, under stirring. This was followed by buffering, using the same volume of TISAB II, at $\mathrm{pH}$ 5.0 , modified by adding $20 \mathrm{~g} \mathrm{NaOH} / \mathrm{L}$ to neutralize the $\mathrm{HCl}$ used in the biopsy. ${ }^{19}$ The firmly bound fluoride formed on the blocks was expressed as $\mu \mathrm{g} \mathrm{F} / \mathrm{cm}^{2}$ for the total $\mathrm{F}$ removed, by adding the amount found in the two layers.

\section{Statistical analysis}

The assumptions of equality of variances and normal distribution of errors were checked by the Shapiro-Wilks test for all the response variables tested, ${ }^{20}$ and the data were analyzed because they did not correspond to the presuppositions of a parametric analysis, according to the nonparametric Kruskal-Wallis and Dunn tests. A significance level of $5 \%$ was considered for all the analyses.

\section{Results}

The sound enamel blocks were selected for the study because of their surface hardness, and showed a mean of $323.1 \pm 14.2 \mathrm{~kg} / \mathrm{mm}^{2}$ (Knoop hardness number). After induction of caries-like lesions, 60 enamel blocks were selected based on their surface hardness value, which was $214.5 \pm 14.3 \mathrm{~kg} / \mathrm{mm}^{2}$.

Table 1 presents the percentage of surface hardness loss (\%SHL) of the dental blocks, according to the different experimental groups, and the percentage of surface hardness recovery (\%SHR) after exposure to the treatments. There was no statistically significant difference among the groups in regard to \%SHL, before the treatments. An increase in \%SHR was observed in all the groups treated with fluoride, mainly in the group treated with iontophoresis at the intensity of $0.8 \mathrm{~mA}$; this group showed the highest median values. However, no significant difference was observed among the groups treated with fluoride

Table 1. Median values (maximum and minimum) of percentage of surface hardness loss (\%SHL) and of surface hardness recovery (\%SHR) of the dental blocks in the different groups $(n=10)$.

\begin{tabular}{lll}
\hline Group & \multicolumn{1}{c}{$\% \mathrm{SHL}^{*}$} & $\% \mathrm{SHR}$ \\
\hline Negative Control & $31.91(39.96 ; 28.03)$ & $-0.15(-5.42 ; 1.27) \mathrm{c}$ \\
$\mathrm{F}_{\text {no-current }}$ & $34.16(40.26 ; 29.48)$ & $1.72(-0.45 ; 10.87) \mathrm{bc}$ \\
$\mathrm{F}_{0.1 \mathrm{~mA}}$ & $34.28(39.15 ; 28.44)$ & $2.49(0.92 ; 34.48) \mathrm{abc}$ \\
$\mathrm{F}_{0.2 \mathrm{~mA}}$ & $33.61(41.09 ; 28.50)$ & $3.24(0.57 ; 11.26) \mathrm{abc}$ \\
$\mathrm{F}_{0.4 \mathrm{~mA}}$ & $33.65(40.08 ; 29.17)$ & $9.80(3.54 ; 22.19) \mathrm{ab}$ \\
$\mathrm{F}_{0.8 \mathrm{~mA}}$ & $33.43(39.55 ; 28.85)$ & $19.88(8.89 ; 33.43) \mathrm{a}$ \\
\hline
\end{tabular}

*No statistical difference was observed among the groups in regard to \%SHL. Means followed by distinct letters significantly differ from one another $(p<0.05)$. 
Table 2. Median values (minimum and maximum value) of calcium fluoride $\left(\mathrm{CaF}_{2} ; \mu \mathrm{g} \mathrm{F} / \mathrm{cm}^{2}\right)$ and fluorapatite $\left(\mathrm{FA} ; \mu \mathrm{g} \mathrm{F} / \mathrm{cm}^{2}\right)$ according to the treatments ( $n=10$ /group).

\begin{tabular}{lcl}
\hline Group & $\mathrm{CaF}_{2}\left(\mu \mathrm{g} \mathrm{F} / \mathrm{cm}^{2}\right)$ & $\mathrm{FA}\left(\mu \mathrm{g} \mathrm{F} / \mathrm{cm}^{2}\right)$ \\
\hline Negative Control & $0.74(0.50 ; 4.31) \mathrm{c}$ & $0.003(0.003 ; 0.008) \mathrm{d}$ \\
$\mathrm{F}_{\text {no-current }}$ & $16.57(8.98 ; 35.05) \mathrm{bc}$ & $0.013(0.009 ; 0.015) \mathrm{cd}$ \\
$\mathrm{F}_{0.1 \mathrm{~mA}}$ & $23.07(15.54 ; 38.05) \mathrm{ab}$ & $0.020(0.018 ; 0.029) \mathrm{bcd}$ \\
$\mathrm{F}_{0.2 \mathrm{~mA}}$ & $21.64(6.61 ; 65.67) \mathrm{ab}$ & $0.043(0.026 ; 0.048) \mathrm{abc}$ \\
$\mathrm{F}_{0.4 \mathrm{~mA}}$ & $26.18(14.06 ; 43.61) \mathrm{ab}$ & $0.064(0.046 ; 0.069) \mathrm{ab}$ \\
$\mathrm{F}_{0.8 \mathrm{~mA}}$ & $34.28(20.22 ; 96.68) \mathrm{a}$ & $0.138(0.095 ; 0.191) \mathrm{a}$ \\
\hline
\end{tabular}

Medians followed by distinct letters differ from one another $(p<0.05)$.

gel and iontophoresis, regardless of the intensity of the current applied.

According to the data shown in Table 2, iontophoresis was seen to interfere with the formation of $\mathrm{CaF}_{2}$ on the enamel surface. Even though the groups treated with fluoride gel and with currents of 0.1, 0.2 and $0.4 \mathrm{~mA}$ did not statistically differ from one another or from the group with fluoride gel and no application of current, the group treated with fluoride and a current of $0.8 \mathrm{~mA}$ showed a greater amount of $\mathrm{CaF}_{2}$ on the surface of the enamel, thus differing statistically from the fluoride group with no current application. Analyzing the effect of iontophoresis on fluorapatite (FA) uptake in enamel with caries-like lesions, the group treated with fluoride and a current of $0.8 \mathrm{~mA}$ showed the greatest amount of FA formed, statistically differing from the fluoride group with no current application and the fluoride group with a current application of $0.1 \mathrm{~mA}$.

\section{Discussion}

The present investigation used a gel prepared with carboxymethylcellulose, a polymer accepted for pharmaceutical use in different application sites. ${ }^{17}$ Its use as a vehicle for iontophoresis is beneficial, since it is inert under physiological conditions, nontoxic, and has thermal stability. ${ }^{17}$ The pharmaceutical form of iontophoretic release of a drug can be liquid or semi-solid, but should be hydrophilic to allow the passage of electric current. Most of the time, aqueous solutions are used to incorporate the drug to be released. However, hydrophilic gels also have the ability to conduct electric current, and because they are viscous solutions, they remain at the application site, and do not spread out, as occurs with other aqueous solutions. Moreover, the permanence of the formulation at the application site offers greater therapeutic efficacy. ${ }^{17}$

During iontophoresis, the fluoride ions in gel formulation come into contact with the cathode (negative electrode) and move towards the anode, whereas the $\mathrm{Ca}^{+2}$ in the hydroxyapatite crystalcomposing the tooth enamel-moves in the opposite direction. This movement of ions seems to facilitate the interaction of fluoride with calcium, to form $\mathrm{CaF}_{2}$. As noted in Table 2, the application of an electrical current of greater intensity $(0.8 \mathrm{~mA})$ resulted in increased formation of $\mathrm{CaF}_{2}$. Apparently, a more intense electric current serves to facilitate both the migration of $\mathrm{Ca}^{+2}$ from the hydroxyapatite, and the consequent formation of $\mathrm{CaF}_{2}$. The gradual increase in the intensity of the electric current also seems to facilitate the release of $\mathrm{PO}_{4}{ }^{2-}$ from the hydroxyapatite crystal, which favors FA formation (Table 2).

Incorporation of fluoride ions in deeper layers of the teeth required application of higher intensities of electric current. In this respect, the present study investigated using carboxymethylcellulose gel to apply fluoride and to conduct the electrical currents selected for this study $(0.1,0.2,0.4$ and $0.8 \mathrm{~mA})$ steadily through the circuit formed using the dental block and $\mathrm{Ag} / \mathrm{AgCl}$ electrodes, for $4 \mathrm{~min}$. It's noteworthy to mention that the maximum electric current applied in this study was $0.8 \mathrm{~mA}$ due to reports in the literature that applying an electric current greater than $1 \mathrm{~mA}$ can damage odontoblasts, causing damage to the dental pulp. ${ }^{21}$ 
This maximum current density was chosen based on other scientific publications. Several articles demonstrate the application of this technique in soft tissues, with a current intensity ranging from 0.1 to $0.8 \mathrm{~mA} / \mathrm{cm}^{2} \cdot{ }^{22,23,24,25}$ This low intensity current was proposed for application to an exposed tooth, because it would not promote significant and detectable alterations in the macro amplitude of the dental structure. The use of current and time intensity values was chosen considering the safety of the process; the values were proposed and substantiated by findings in the literature applied to biological membranes and tissues. ${ }^{22,23,24,25}$ Critically evaluating the application of this dental technique in a more global context could attract additional research to clarify the effects of different electric current intensities on the histological and functional characteristics of soft tissues, as a proposal for a new study.

Unlike the study by Kim and Kim, ${ }^{26}$ our objective was not to evaluate enamel remineralization after the fluoride iontophoresis treatment of the blocks with caries-like lesions. Our study conducted only one application of fluoride iontophoresis, and the enamel blocks were not subsequently exposed to artificial saliva. Moreover, enamel surface hardness was the parameter used to select the sound blocks and those with caries-like lesion, so that the experimental groups would not statistically differ in regard to
\%SHL before application of the treatments. The slight surface hardness recovery shown by the enamel blocks both treated and not treated with fluoride under iontophoresis was merely the result of fluoride precipitation in the outermost enamel layer. A limitation of our study is that the higher amount of fluoride uptake may not necessarily have a preventive or reparative effect. Nevertheless, these effects should be tested in future studies using other methodologies.

Further studies testing other concentrations and formulations of fluoride should also be conducted. It would indeed be interesting to test fluoride iontophoresis in a $\mathrm{pH}$-cycling regimen to verify whether there is any difference in fluoride release from calcium fluoride formed from fluoride iontophoresis, compared with other fluoride products.

\section{Conclusion}

Iontophoresis at $0.8 \mathrm{~mA}$, combined with the application of fluoridated gel $(2 \% \mathrm{NaF})$, increased the fluoride uptake in enamel with caries-like lesions, as either calcium fluoride or fluorapatite.

\section{Acknowledgments}

The authors would like to thank CAPES and FAPESP (2011/04908-1) for their financial support.

\section{References}

1. Khan A, Yasir M, Asif M, Chauhan I, Singh AP, Sharma R, et al. Iontophoretic drug delivery: history and applications. J Appl Pharm Sci. $2011 ; 1(3): 11-24$.

2. Cubayachi C, Couto RO, de Gaitani CM, Pedrazzi V, Freitas O, Lopez RF. Needle-free buccal anesthesia using iontophoresis and amino amide salts combined in a mucoadhesive formulation. Colloids Surf B Biointerfaces. 2015 Dec;136(1):1193-201. https://doi.org/10.1016/i.colsurfb.2015.11.005

3. Santana DC, Dias K, Souza JG, Ogunjimi AT, Souza MC, Silva RS, et al. NO exchange for a water molecule favorably changes iontophoretic release of ruthenium complexes to the skin. Molecules. 2017 Jan;22(1):104-18. https://doi.org/10.3390/molecules22010104

4. Souza JG, Dias K, Silva SA, de Rezende LC, Rocha EM, Emery FS, et al. Transcorneal iontophoresis of dendrimers: PAMAM corneal penetration and dexamethasone delivery. J Control Release. 2015 Feb;200(28):115-24. https://doi.org/10.1016/i.jconrel.2014.12.037

5. Souza JG, Dias K, Pereira TA, Bernardi DS, Lopez RF. Topical delivery of ocular therapeutics: carrier systems and physical methods. J Pharm Pharmacol. 2014 Apr;66(4):507-30. https://doi.org/10.1111/iphp.12132

6. Schmitt JV, Miot HA. Randomized, double-blind, controlled topical anesthesia induced by iontophoresis of lidocaine. Surg Cosmetic Dermatol. 2009;1(3):112-4.

7. Wei R, Simon L, Hu L, Michniak-Kohn B. Effects of iontophoresis and chemical enhancers on the transport of lidocaine and nicotine across the oral mucosa. Pharm Res. 2012 Apr;29(4):961-71. https://doi.org/10.1007/s11095-011-0636-x 
8. Singal P, Gupta R, Pandit N. 2\% sodium fluoride-iontophoresis compared to a commercially available desensitizing agent. J Periodontol. 2005 Mar;76(3):351-7. https://doi.org/10.1902/jop.2005.76.3.351

9. Fejerskov O. Changing paradigms in concepts on dental caries: consequences for oral health care. Caries Res. 2004 MayJun;38(3):182-91. https://doi.org/10.1159/000077753

10. Fejerskov O, Kidd EAM, editors. Dental caries: the disease and its clinical management. 2th ed. Oxford: Blackwell Nyvad; 2008.

11. ten Cate JM. Review on fluoride, with special emphasis on calcium fluoride mechanisms in caries prevention. Eur J Oral Sci. 1997 Oct;105(5 Pt 2):461-5. https://doi.org/10.1111/j.1600-0722.1997.tb00231.x

12. Petersen PE, Bourgeois D, Ogawa H, Estupinan-Day S, Ndiaye C. The global burden of oral diseases and risks to oral health. Bull World Health Organ. 2005 Sep;83(9):661-9. https://doi.org/10.1590/S0042-96862005000900011

13. White DJ. Reactivity of fluoride dentifrices with artificial caries. I. Effects on early lesions: F uptake, surface hardening and remineralization. Caries Res. 1987;21(2):126-40. https://doi.org/10.1159/000261013

14. Fushida CE, Cury JA. [In situ evaluation of enamel-dentin erosion by beverage and recovery by saliva]. Rev Odontol Univ Sao Paulo. 1999;13(2):127-34. Portuguese. https://doi.org/10.1590/S0103-06631999000200005

15. Queiroz CS, Hara AT, Paes Leme AF, Cury JA. pH-cycling models to evaluate the effect of low fluoride dentifrice on enamel de- and remineralization. Braz Dent J. 2008;19(1):21-7. https://doi.org/10.1590/S0103-64402008000100004

16. Moreno EC, Zahradnik RT. Chemistry of enamel subsurface demineralization in vitro. J Dent Res. 1974 Mar-Apr;53(2):226-35. https://doi.org/10.1177/00220345740530020901

17. Gratieri T, Gelfuso GM, Lopez RF. Basic principles and applications of iontophoresis for cutaneous penetration of drugs. Quim Nova. 2008;31(6):1490-8. https://doi.org/10.1590/S0100-40422008000600040

18. Caslavska V, Moreno EC, Brudevold F. Determination of the calcium fluoride formed from in vitro exposure of human enamel to fluoride solutions. Arch Oral Biol. 1975 May-Jun;20(5-6):333-9. https://doi.org/10.1016/0003-9969(75)90023-0

19. Koo RH, Cury JA. Soluble calcium/SMFP dentifrice: effect on enamel fluoride uptake and remineralization. Am J Dent. 1998 Aug;11(4):173-6.

20. Box GE, Hunter JS, Hunter WG. Statistics for experimenters: design, innovation, and discovery. 2nd ed. New York: Wiley; 2009.

21. Scott HM. Reduction of sensitivity by electrophoresis. ASDC J Dent Child. 1962;29:225-41.

22. Ebihara M, Akiyama M, Ohnishi Y, Tajima S, Komata K, Mitsui Y. lontophoresis promotes percutaneous absorption of L-ascorbic acid in rat skin. J Dermatol Sci. 2003 Sep;32(3):217-22. https://doi.org/10.1016/S0923-1811(03)00105-1

23. Pacini S, Punzi T, Gulisano M, Ruggiero M. Pulsed current iontophoresis of hyaluronic acid in living rat skin. J Dermatol Sci. 2006 Dec;44(3):169-71. https://doi.org/10.1016/i.jdermsci.2006.08.012

24. Dubey S, Kalia YN. Non-invasive iontophoretic delivery of enzymatically active ribonuclease A (13.6 kDa) across intact porcine and human skins. J Control Release. 2010 Aug;145(3):203-9. https://doi.org/10.1016/i.jconrel.2010.04.020

25. Gelfuso GM, Gratieri T, Delgado-Charro MB, Guy RH, Vianna Lopez RF. Iontophoresis-targeted, follicular delivery of minoxidil sulfate for the treatment of alopecia. J Pharm Sci. 2013 May;102(5):1488-94. https://doi.org/10.1002/ips.23485

26. Kim HE, Kim BI. Can the application of fluoride iontophoresis improve remineralisation of early caries lesions? Oral Health Prev Dent. 2016;14(2):177-82. https://doi.org/10.3290/i.ohpd.a35007 


\title{
Effect of iontophoresis on fluoride
} uptake in enamel with artificial caries lesion. Braz Oral Res. 2018;33:e037.

\author{
Author's name \\ Where is read: Cintia Pereira MACHADO \\ It should read: Cintia Pereira Machado TABCHOURY \\ Legend \\ Where is read: Pauli MC, Machado CP, Silva SAM, Ambrosano GMB, \\ Lopez RFV, Leonardi GR \\ It should read: Pauli MC, Tabchoury CPM, Silva SAM, Ambrosano GMB, \\ Lopez RFV, Leonardi GR
}

http://dx.doi.org/10.1590/1807-3107bor-2019.vol33.0037erratum 